\title{
Digitizing Native American Collections
}

\author{
Nora Stewart
}

Note from the editor: DttP has been featuring student papers for a number of years at this point-I remember talking about it in my documents class in library school. (For the record, I did not get nominated, which was probably the right choice, even if I did find my paper about the Nuclear Regulatory Commission fascinating.) But as technology changes the work of libraries, so has it changed the products that our students are producing. What follows is an example of a libguide created by a Nora Stewart, student from Emporia State University. Although my presentation of this work is somewhat clumsy, I highly recommend that all of you visit the page (http:/libguides.emporia.edu/c.php?g=531631\&p=3637209) and look through the resources Nora has collected and placed into context.

Prepared as part of the course LI838XI Government Resources (Summer 2016) at Emporia State University, School of Library and Information Management. Available at http://libguides .emporia.edu/digitizingnativeamericancollections.

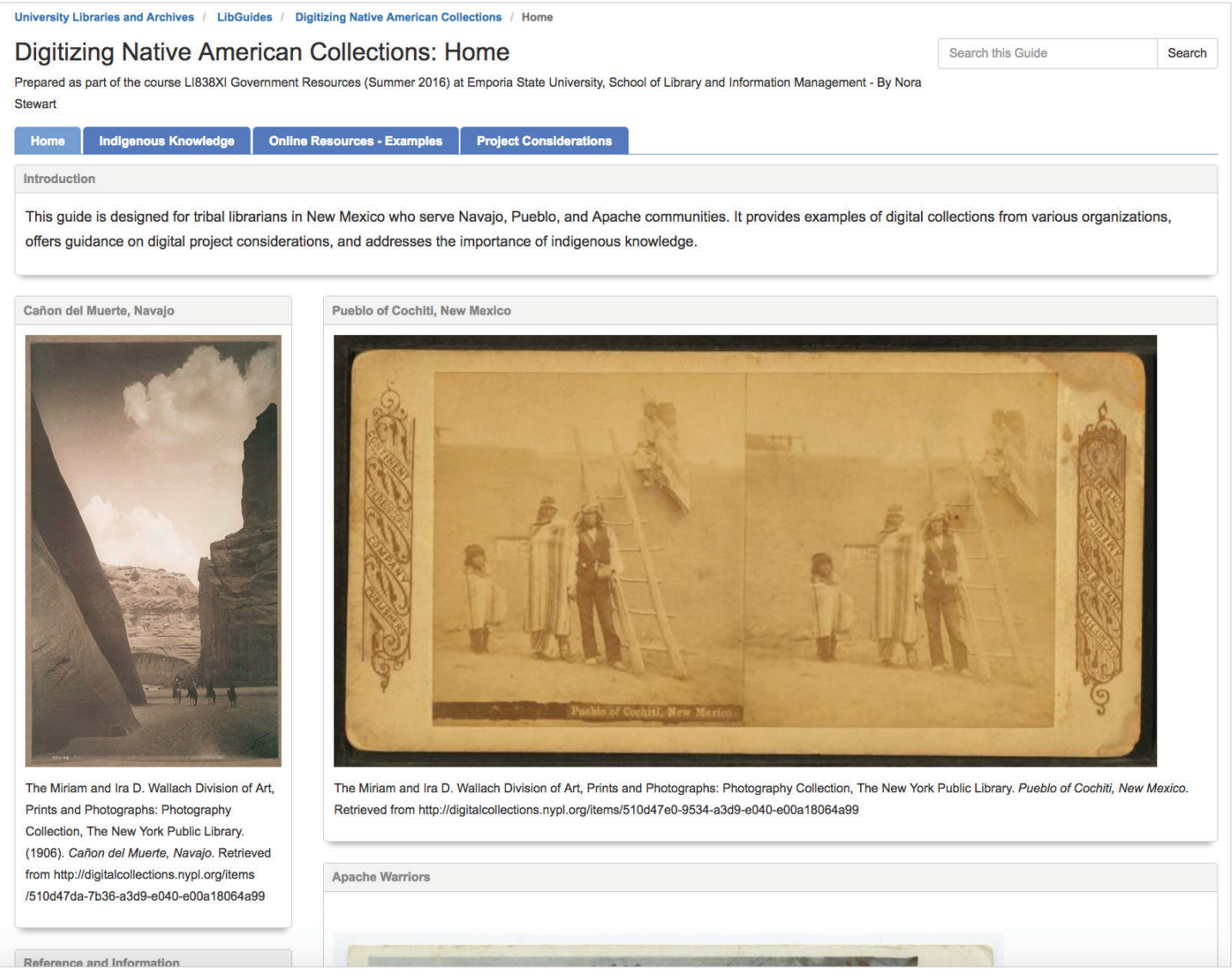

Homepage 


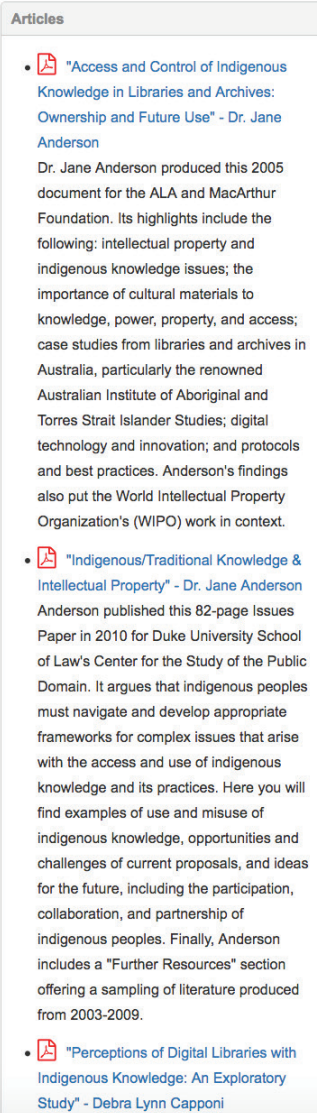

- $\triangle \Delta$ "Perceptions of Digital Libraries with Indigenous Knowledge: An Exploratory Study" - Debra Lynn Capponi

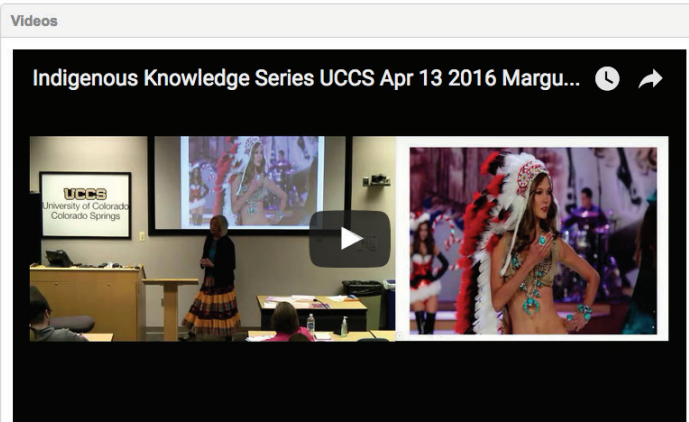

This video contains footage from the Indigenous Knowledge Series in April 2016 at the University of Colorado - Colorado Springs

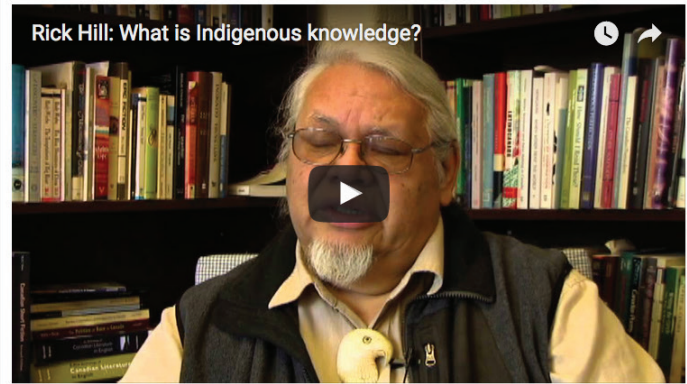

Rick Hill (Tuscarora), artist, writer, and curator who lives at the Six Nations Community of the Grand River Territory in Ontario, Canada, presents a brief description of indigenous knowledge. Mr. Hill has been involved in indigenous knowledge efforts in many capacities over the years, including that of Director of the Indian Museum at the IAIA in Santa Fe, New Mexico and Assistant Director for Public Programs at the NMAl. He also has been involved in the management of the Six Nations Virtual Archives Project.

Websites

- Center for World Indigenous Studies (CWIS)

The CWIS was founded in 1984 by members of the Cowlitz Tribe and Shuswap Nation in response to requests by the Conference of Tribal Government in

\section{Indigenous Knowledge}

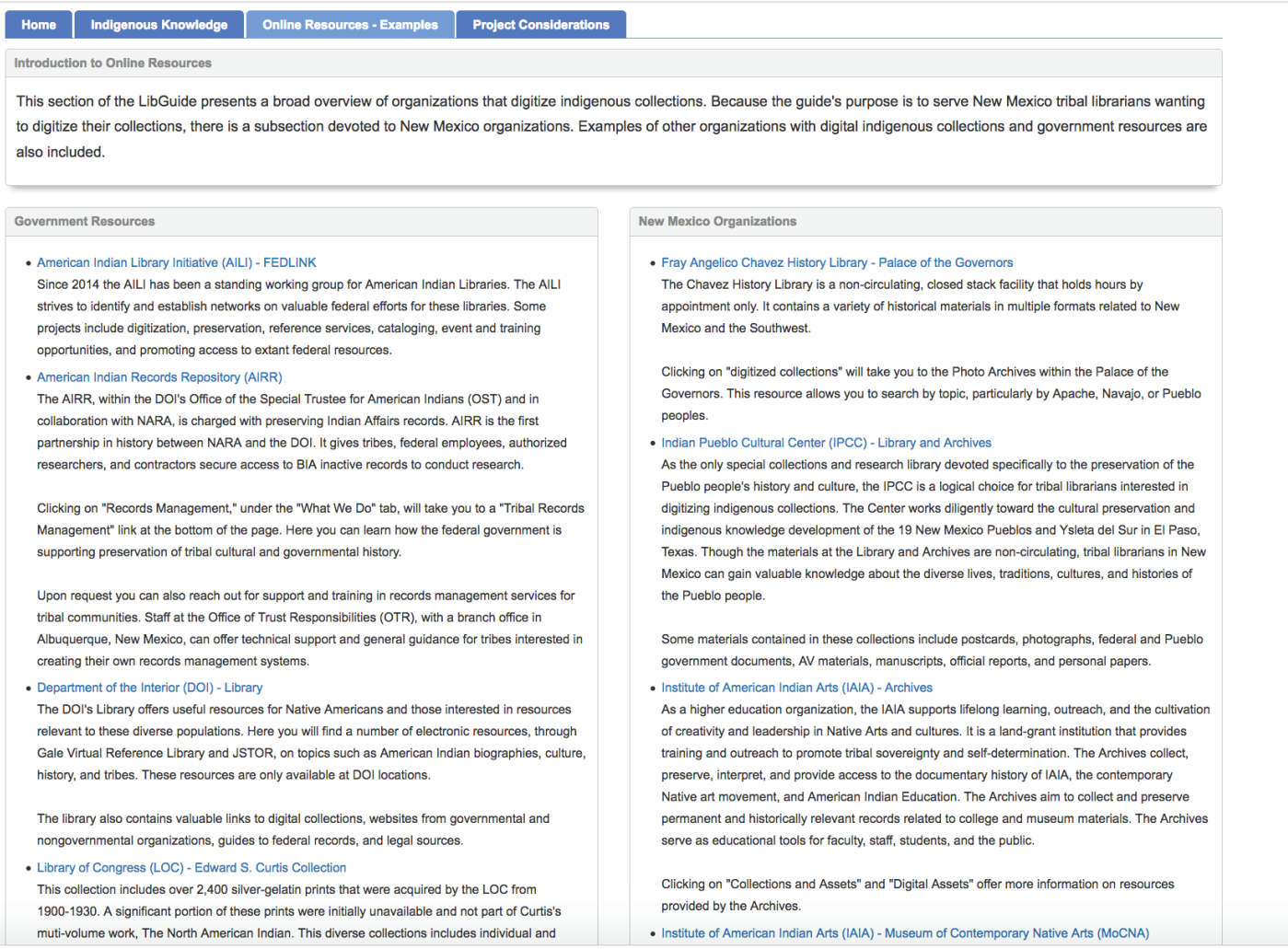

Online Resources 
- New York Public Library (NYPL) - Digital Collections

NYPL's Digital Collections offer nearly 700,000 digitized items. By browsing their digital collections, using the keyword search "American Incian," you can find a variety of digitized items, including photos, postcards, and drawings. Likewise, using the terms "Navajo," "Pueblo," or "Apache" yields multiple results

- Simon Fraser University - Indigenous Collections

Simon Fraser University Digitized Collections Includes the extensive Indigenous Collections, some (a) pulch lo peoples of the Pacilic Nortwest, the Norhern Uustce Society Natve Crime Bibliography that highlights research, policy, and programs on Native involvement with the criminal justice system in the U.S. and abroad, and the White Mountain Apache Collection that includes U.S. government a legal documents on land claims and other issues related to the White Mountain Apache Tribe in Arizona

- Southem Oregon University Hannon Library - Southern Oregon Archives (SODA)

SODA contains rich digital archives on various subjects. The Dean and Mary Collins Collection holds 100 digital versions of material objects representing Native American artifiacts from the Southwest. The First Nations Collection covers books, articles, and documents related to the indigenous peoples of the Siskiyou-Cascade-Klamath bioregion. Materials pertinent to tribes of southwestern Oregon and northern California, including the Coos, Hupa, Karuk, Klamath, Takelm Shasta, Modoc, Siuslaw, Yahooskin, Yurok, and Cow Creek Band of Umpqua, are represented. This collection serves as an educational resource on the indigenous peoples of the region. Collection owners have collaborated with tribes and tribal representatives to create a more comprehensive database that includes treaties, Congressional hearings, Bureau of Indian Affairs (BIA) publications, tribal language dictionaries, and much moro.

- Yale University - Indian Papers Project (YIPP)

Though the YIPP focuses on documenting the history of Native Americans in New England, tribal librarians in New Mexico can learn from this example. Significant collaboration between Institutional, contributing, consortial, and tribal partners has taken place to implement and maintal the project. By clicking on "Collection," followed by "How to Search the Collection," you will gain access to nearly 400 years of New England Native American primary source materials. In doing so. the YIPP gives multiple audiences, including educators, students, researchers, tribal members, and the general public, increased access to significant historical knowledge. Strict adherence to best practices and scholary, archival, and technical standards is followed and serves other organizations wanting to begin their own digital projects.

Navajo woman weaving on upright loom with family

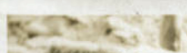

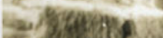

puts Native American issues and histories in a larger framework, particularly as they relate to indigenous knowledge

Vidoos

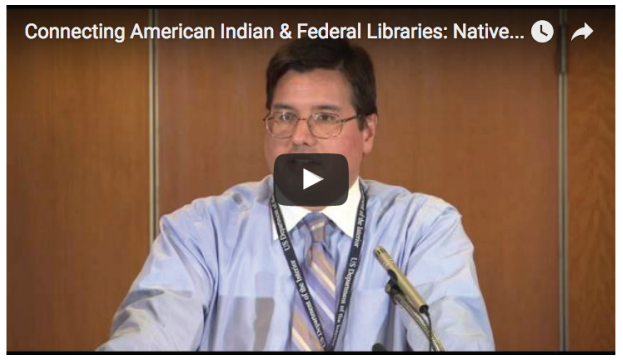

The LOC recently provided the above video that presents information on FEDLINK's AlLI. Here you will find a panel of American Indian historians and cultural experts talking about regional and federal culture and history and be given a demonstration of the Indigenous Tribal Law Project, a free, online resource to increase access and discoverability of tribal law through tribal listings, websites, and online primary source materials.

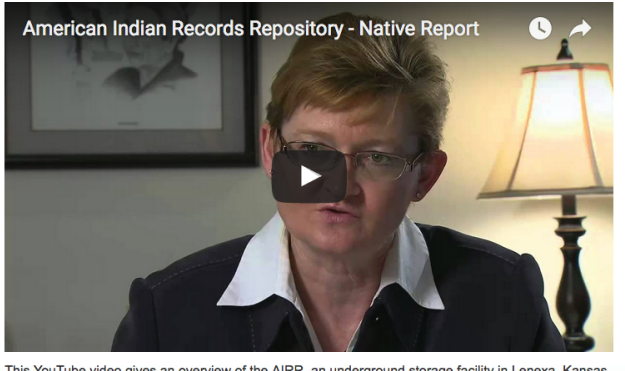

Additional Online Resources 